\title{
Land Conservation in the Gulf of Mexico Region: A Comprehensive Review of Plans, Priorities, and Efforts
}

\author{
Sathishkumar Samiappan 1,*(-), Andrew Shamaskin ${ }^{2}$, Jiangdong Liu ${ }^{2}$, Jennifer Roberts ${ }^{2}$, \\ Anna Linhoss ${ }^{1,3}$ and Kristine Evans ${ }^{2}$ \\ 1 Geosystems Research Institute, Mississippi State University, Mississippi State, MS 39762, USA \\ 2 Department of Wildlife, Fisheries, and Aquaculture, Mississippi State University, Mississippi State, MS \\ 39762, USA; acs920@msstate.edu (A.S.); jiangdong.liu@msstate.edu (J.L.); jennifer.roberts@msstate.edu (J.R.); \\ kristine.evans@msstate.edu (K.E.) \\ 3 Agricultural and Biological Engineering, Mississippi State University, Mississippi State, MS 39762, USA; \\ alinhoss@abe.msstate.edu \\ * Correspondence: sathish@gri.msstate.edu; Tel.: +1-662-325-4049
}

Received: 29 April 2019; Accepted: 21 May 2019; Published: 23 May 2019

\begin{abstract}
An unprecedented land conservation effort is presently underway in the Gulf of Mexico Coastal Region (GCR) due to an influx of funds from settlements related to the 2012 RESTORE Act. A complete understanding of the priorities of the states in the GCR is critical to ensure that land conservation planning efforts are implemented effectively and efficiently. The paper reviews past, current, and future land conservation priorities in the GCR to inform strategic planning efforts. This review catalogs an extensive list of projects and plans proposed and implemented at federal, state, county, and city levels with direct ties to land conservation during the past 20 years. Comprehensive restoration goals proposed by the Gulf Coast Ecosystem Restoration (Restore) Council were used as a framework for grouping priorities within conservation plans and projects. Plans were first compiled via internet searches and expert sources, then a series of eight stakeholder charrettes were held across the GCR states to validate the catalog and add missing projects and plans. A geospatial web tool was developed using the Restore Council goal framework to allow for the identification and exploration of plans in the GCR.
\end{abstract}

Keywords: conservation priorities; conservation planning; strategic planning; habitat protection

\section{Introduction}

The United States (US) Gulf of Mexico Coastal Region (GCR) contains a vast and diverse natural landscape, which includes coastal wetlands, submerged vegetation, bayous, uplands, and offshore marine areas (Figure 1). Encompassing more than 700,000 square km, the GCR harbors over 15,000 species of flora and fauna [1]. This biodiversity is a product of the breadth of ecosystems represented within the GCR landscape. The five adjoining states in the GCR, including parts of Alabama (AL), Florida (FL), Louisiana (LA), Mississippi (MS), and Texas (TX), are also places of rich culture and great natural beauty, with deep socioeconomic ties to the abundant natural resources in the region. Since natural and societal values depend on the ecological richness of the region, conservation is a shared priority among many GCR stakeholders. However, years of ecological degradation [2-5], including the effects of the 2010 Deepwater Horizon disaster and oil spill, have increased the vulnerability of resources within the region.

The US has a long history of practicing land conservation at all levels of government resulting in a robust network of protected lands in the GCR [6]. However, a persistent conservation planning 
challenge is the identification of optimal lands in need of protection and subsequent prioritization of those areas based on ecological and socioeconomic valuations. As it is not possible to protect all the land worth protecting within a region at the same time, a strategic approach must be used to identify the most effective lands to conserve relative to ecological and socioeconomic goals [7]. However, substantial lands remain vulnerable to conversion, and, to date, there is a lack of comprehensive analysis of land conservation planning efforts across the entire GCR geography to improve strategic targeting of land conservation efforts. A holistic understanding of the extent and focuses of existing conservation efforts in the GCR will help planners direct appropriate conservation actions in the future. With private land ownership dominating over $86 \%$ of agricultural and forested lands in the GCR, conservation and management decisions involving private landowners has a significant impact on the region's environment and economy [8]. Proactive engagement with state and federal agencies, private landowners, local communities, and nonprofit organizations that actively conserve land via joint agreements with landowners, direct land purchases, and other methods will be paramount to create a sustainable future for the GCR.

In response to the Deepwater Horizon oil spill of 2010, the US government acted in concert with states to implement coordinated efforts to restore the ecosystems and economy of the GCR. Included in the federal response is the Resources and Ecosystems Sustainability, Tourist Opportunities, and Revived Economies of the Gulf Coast States (RESTORE) Act, signed into law in July 2012 [9]. The RESTORE Act created the Gulf Coast Ecosystem Restoration Council (Council) and the Gulf Coast Restoration Trust Fund (Trust Fund). The RESTORE Council consists of 11 members, including leaders of six federal departments and governors of the five Gulf Coast states. One of the Council's responsibilities is the development of a comprehensive plan for the restoration of the Gulf Coast. The Trust Fund is responsible for obligating 80 percent of the Clean Water Act penalties generated from the oil spill with the funds going towards accomplishing goals and objectives identified in the RESTORE Council's comprehensive plan [10]. These goals include Restore and Conserve Habitat (Habitat), Restore Water Quality (Water Quality), Replenish and Protect Living Coastal and Marine Resources (LCMR), Enhance Community Resilience (Community Resilience), and Restore and Revitalize the Gulf Economy (Gulf Economy). For clarity, we will hereafter refer to each RESTORE goal in the text as they appear in parenthesis in the previous sentence. The Strategic Conservation Assessment (SCA) project, funded by the Department of Interior (DOI) via the Council Selected Restoration Component, is focused on developing science-based conservation planning support tools using the RESTORE goal framework to maximize the effectiveness of land conservation investments. In this work, one of these tools is presented that catalogs existing conservation plans in the form of geospatial visualization.

A holistic understanding of the origin of conservation plans and their relationship with respect to RESTORE conservation goals can be useful in understanding and aligning conservation planning efforts to funding opportunities associated with land conservation in the GCR. Similar comprehensive analyses of conservation effort have been conducted in Australia and Europe [11,12]. The outcomes of such research found an uneven representation of habitat protections across their respective regions and characterized the frequency of conservation at different planning extents. While our study has a similar vein of analysis, it is distinguished by our characterization of conservation efforts within the framework of the RESTORE goals which represent the shared priorities of the GCR. We focus on the RESTORE goals framework because of the unique opportunity to fund conservation efforts from the influx of funds from settlements related to the 2012 RESTORE Act. The product of this study will thus summarize how land conservation across the GCR has addressed the RESTORE goals, with the intent that it will help illuminate and guide appropriate conservation actions that provide adequate protections for the region's diverse landscape, species, and economic activity.

In this study, we compiled and reviewed an extensive inventory of conservation plans in the Gulf of Mexico-from local to regional (i.e., GCR) levels-to catalog priorities identified and efforts undertaken with respect to land conservation. With respect to RESTORE goals, we expect plans to more frequently address Habitat, Water Quality and LCMR. Whereas socioeconomic goals such as 
Community Resilience and Gulf Economy are not typically addressed through land conservation, we therefore expect these goals to occur less frequently. This study is the first large-scale regional assessment of conservation planning efforts across governmental, nongovernmental, and nonprofit organizations encompassing all ecosystem types in the GCR. This comprehensive analysis is vital to understanding the key factors that may drive existing conservation efforts, as well as identify potential gaps in conservation planning efforts.

The contributions of this study include

1. a catalog of conservation plans and projects in the GCR at multiple levels of the jurisdiction from 1998 to 2018;

2. the development of an online geospatial tool for exploring conservation plans in the GCR; and

3. an assessment of how conservation planning at various political and geomorphological subregions within the GCR associates with the RESTORE Council goals.

\section{Materials and Methods}

\subsection{Scope of the Study}

The SCA region of interest aligns with the RESTORE Act-identified GCR, an area of approximately 700,000 square km (Figure 1). The GCR encompasses coastal parts of AL, LA, MS, TX, and all of FL. This geographic extent was created using the coastal management zone area in the five Gulf states, plus a $40.2 \mathrm{~km}$ inland buffer. Some of the plans within the catalog extended outside these limits but were included if benefits directly occurred within the SCA region.

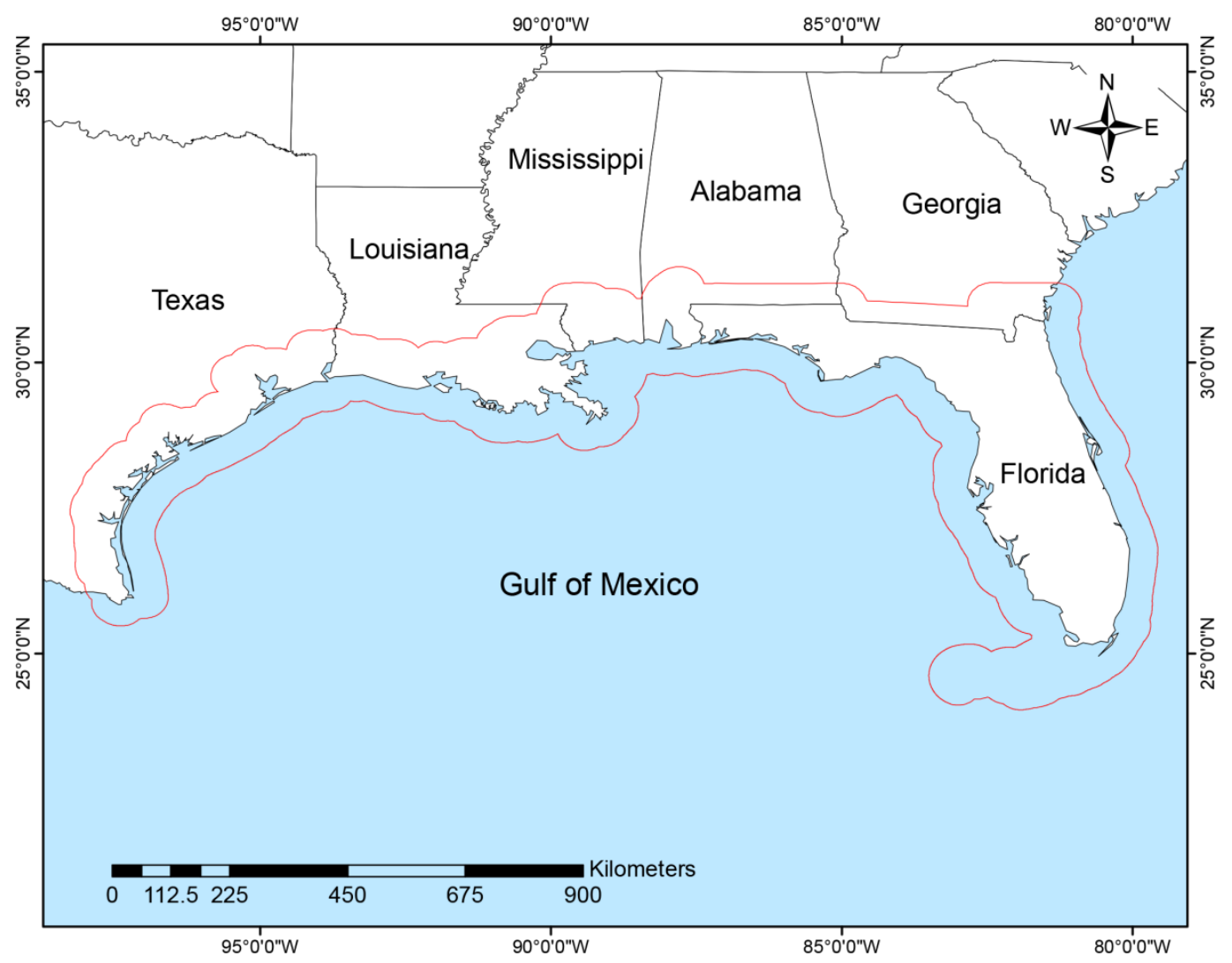

Figure 1. Overview of the Gulf of Mexico Coastal Region (GCR) along the U.S. Gulf of Mexico. The GCR includes all of the coastal counties, plus $40.2 \mathrm{~km}$ inland of the coast including the barrier islands as shown in red outline. 


\subsection{Method for Cataloging Plans}

To represent the breadth of planning scales, the conservation plans were categorized in three ways: by (1) individual states in the GCR; (2) political and geomorphological subregions (Table 1); and (3) the goals identified by the RESTORE Council (Table 2). Some plans extended beyond an individual state and were grouped as GCR plans in lieu of belonging to an individual state. The plans were also grouped by political and geomorphological subregions because of the importance of planning scale towards achieving conservation objectives. Plans with political boundary classifications (i.e., city, county/parish, region (within the state), statewide, and GCR), were developed by the representative political entity and incorporated some land conservation actions. Regional plans had focal areas of two or more cities or counties/parishes within a state and GCR plans had planning scales that spanned multiple states within the GCR. Geomorphological classification scales included coastal habitat for plans with focal areas such as barrier islands, estuaries, and other areas within the coastal zone (e.g., beaches, dunes, and salt marshes), and basin/watershed for plans which used watersheds as planning scales.

Table 1. Political and geomorphological subregions (subregions) considered in the assessment of Gulf Coast plans.

\begin{tabular}{cc}
\hline Category & Subregion Name \\
\hline Geopolitical & City (CY) \\
& $\begin{array}{c}\text { County and Parish (CP) } \\
\text { Regional (REG) } \\
\text { Statewide (ST) }\end{array}$ \\
\hline Geomorphological & Coastal Habitat (CH) \\
& Basin and Watershed (BW) \\
\hline labels in all graphs will refer to subregions by their short forms displayed here.
\end{tabular}

For purposes of this work, we define land conservation as strategic investments in land acquisitions, easements, and stewardship for conservation and/or preservation purposes to protect ecological and socioeconomic values in the GCR. We define acquisition as land acquired from a willing seller who enters into a purchase agreement and sells the title of a property to a land trust or government (i.e., fee title or fee simple). In contrast, easement limits specific uses of the land to achieve specific conservation objectives while keeping the land in the owner's control. Stewardship is a general term for land management, restoration, and maintenance of lands specifically applied here to fee title acquisitions and conservation easements on private lands.

Table 2. Goals identified in the Gulf Coast Ecosystem Restoration Council [10].

\begin{tabular}{|c|c|c|}
\hline & RESTORE Goals & Definition \\
\hline 1 & Restore and Conserve Habitat (HAB) & $\begin{array}{l}\text { Restore and conserve the health, diversity, and resilience of } \\
\text { key coastal, estuarine, and marine habitats. }\end{array}$ \\
\hline 2 & Restore Water Quality (WAQ) & $\begin{array}{l}\text { Restore and protect water quality of the Gulf Coast } \\
\text { region's fresh, estuarine, and marine waters }\end{array}$ \\
\hline 3 & $\begin{array}{c}\text { Replenish and Protect Living Coastal and } \\
\text { Marine Resources (LCMR) }\end{array}$ & $\begin{array}{l}\text { Restore and protect healthy, diverse, and sustainable living } \\
\text { coastal and marine resources }\end{array}$ \\
\hline 4 & Enhance Community Resilience (CRES) & $\begin{array}{l}\text { Build upon and sustain communities with capacity to } \\
\text { adapt to short- and long-term changes }\end{array}$ \\
\hline 5 & $\begin{array}{l}\text { Restore and Revitalize the Gulf } \\
\text { Economy (GEC) }\end{array}$ & $\begin{array}{l}\text { Enhance the sustainability and resiliency of the } \\
\text { Gulf economy }\end{array}$ \\
\hline
\end{tabular}

The RESTORE Council distinguished five goals in their comprehensive plan (Table 2) as a framework for helping to restore the ecosystem and economy of the GCR [10]. For purposes of the SCA project we defined goals as desired ecological and socioeconomic outcomes that can be achieved 
through land conservation. Priorities are components of a single goal that focus on a specific aspect in achieving the goal. Plans are documents compiled by various organizations or government agencies that outline land conservation actions. Projects are plans that are funded for implementation or already implemented. Conservation targets are areas of land that are of interest for land conservation. The vast majority of identified "conservation targets" are formalized in existing plans and databases.

Classifying land conservation plans based on the values or benefits they provide with respect to RESTORE goals bestows conservation planners with an important understanding of conservation efforts within a region. In this work, the conservation plans within the GCR were classified into five groups that reflect the RESTORE goals (Table 2). These goals provide the framework for an integrated restoration approach at local, state, tribal and federal levels.

The conservation community along the GCR represents a diverse set of stakeholders with wide-ranging interests, priorities, and objectives. In this work, the established conservation targets were identified through the Gulf of Mexico Alliance (GOMA), Landscape Conservation Cooperatives (LCCs), Migratory Bird Joint Ventures (JVs), State Wildlife Action Plans (SWAPs), the Partnership for Gulf Coast Land Conservation (PGCLC), National Estuary Programs (NEPs), and many others to forgo the "priority resource setting" process that so often bogs down similar efforts $[13,14]$. To collate these priorities, the SCA project team mined available plans and databases and classified priorities and objectives contained therein by a variety of scales and levels (Tables 1 and 2). This assessment was intended to be extensive, but not exhaustive, as only the primary considerations for conservation needed to be captured for prioritizing the landscape. Cataloging the priorities and objectives in this way enables stakeholders to identify scale mismatches, scale pluralities, and scale omissions that left unresolved would ultimately undermine any overarching effort to unify these individual plans and designs.

Within the study area, an extensive list was created of existing and proposed conservation plans and projects between 1998 and 2018 (see Appendix A). Each plan underwent an initial review which was used to identify the geographic extent of the plan, the conservation strategies (i.e., acquisition, stewardship, and easement) included in the plan, and the RESTORE goal(s) to which the plan is associated (Table 2). To reduce subjectivity, a second reviewer independently recorded the same information for cross-validation. A plan's review was considered complete if the two reviews were identical. Otherwise, a third reviewer was used to settle differences. Only plans that addressed at least one conservation strategy as part of the plan content were included in the final inventory.

From March to May 2018, the SCA project team held charrettes with stakeholders across the GCR to discuss the inventory of plans and conservation priorities and identify other priorities for land conservation within the framework of the RESTORE goals. Stakeholders in attendance were representatives from various RESTORE member and partner agencies, and organizations that engage in conservation actions. A total of eight charrettes were conducted within the GCR (Austin, Corpus Christi, and Galveston, Texas; New Orleans, Louisiana; Biloxi, Mississippi; Mobile, Alabama; St. Mark's and St. Petersburg, Florida) where 176 stakeholders worked with the SCA project team to (1) review and discuss priorities that land conservation strategies can address; (2) develop a weighted list of shared priorities; (3) brainstorm a list of measures for each of the priorities; (4) rank the five RESTORE goals with respect to land conservation strategies; and (5) verify the data catalog and report missing plans/projects.

\subsection{Online Catalog of Conservation Plans}

The dispersed nature and a lack of single portal access make it difficult for people to effectively and efficiently discover and learn about conservation plans in the GCR. Conservation researchers and organizations often have trouble finding these plans due to the distributed nature of the websites that host them. As users increasingly prefer to take advantage of geospatial data visualization methodologies, an online web portal was developed to organize plans that were analyzed in this work (Figure 2). The catalog was published online as a geospatial web tool, which can be accessed at 
http://bit.ly/sca_gulf, which will serve as an aggregate of plans and projects in the GCR. This portal also allows users to report missing plans. Since the tool was launched in December 2017, it has been accessed 368 times.

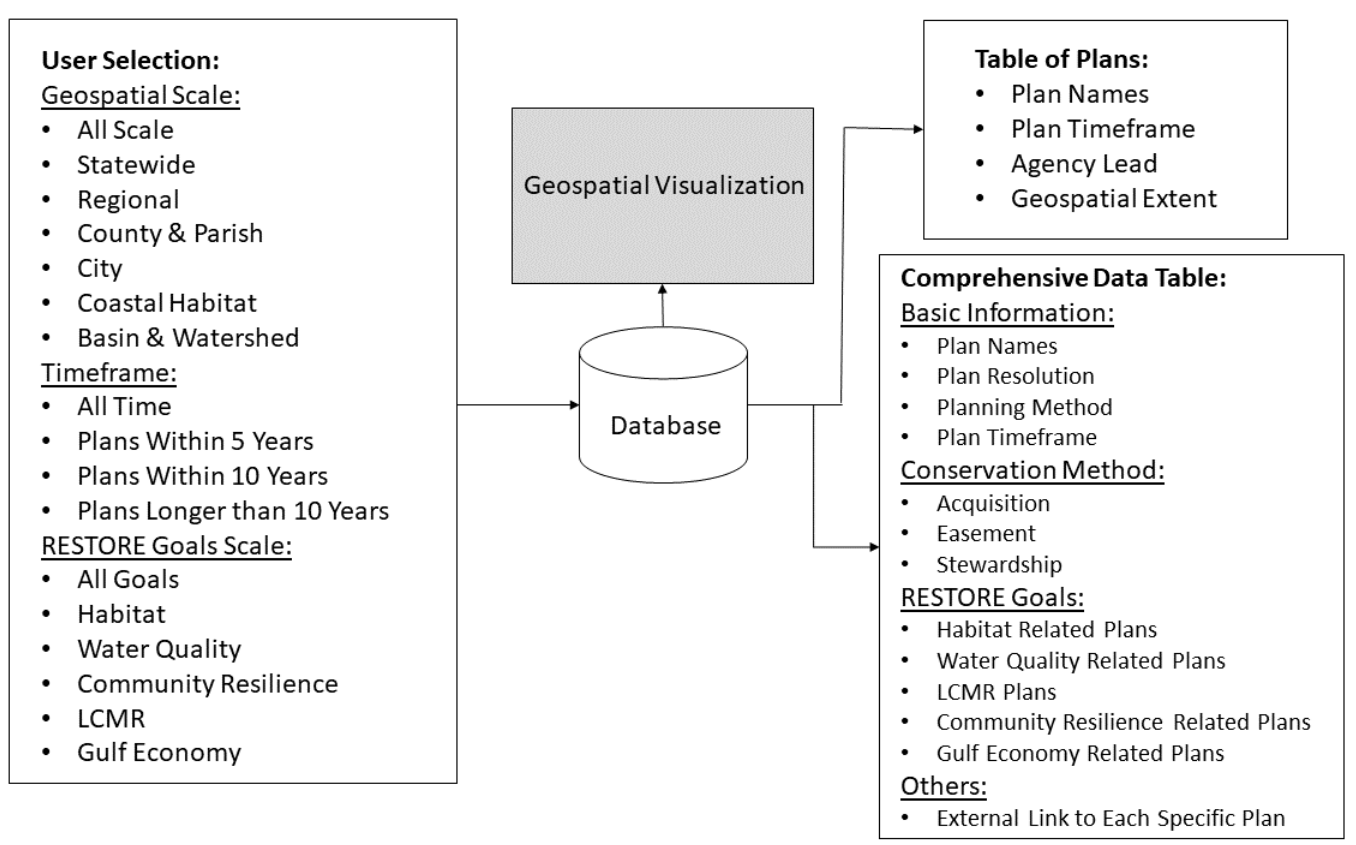

Figure 2. The site map of the geospatial online visualization tool and catalog detailing the structure, high-level functionality, user options, and navigation scheme.

\subsection{Summary of Data}

The catalog of plans was summarized by the state of origin, by political and geomorphological subregions (Table 1), and by political and geomorphological subscales within each state, to compare how conservation plans associated with RESTORE goals (Table 2) at each geo-extent. How each geo-extent of conservation planning associates with RESTORE goals was measured by the percentage of plans at each geo-extent that contain objectives that are associated with a particular RESTORE goal. In total, three summaries of conservation plans were made (i.e., by state, by political and geomorphological subscales, and by political and geomorphological subscales within each state) from the catalog that describes the percentage of plans that align with each RESTORE goal. The results of these summaries were then used to understand how consistently RESTORE Goals are addressed by conservation planning throughout the GCR.

\section{Conservation Plan Analysis}

\subsection{RESTORE Goals by State}

We gathered 352 plans from communities, NGOs, and state and federal agencies for our initial efforts, and found 293 of those that included some form of land conservation (i.e., acquisition, easement, and stewardship). From the catalog of plans, the majority from each state include LCMR $(65-77 \%)$ as well as Habitat (53-92\%) as conservation priorities (Figure 3). Overall, the minority of plans focus on enhancing community resilience or revitalizing the Gulf economy, with LA-based plans addressing these goals at the highest rate ( $47 \%$ and $43 \%$, respectively). Water quality is addressed in conservation planning at varying rates depending on the state. The majority of FL and LA plans (82\% and 57\%, respectively) consider water quality conservation targets, while the minority of plans from other states and gulf-wide plans address this goal. 
Focus of RESTORE Goals by State

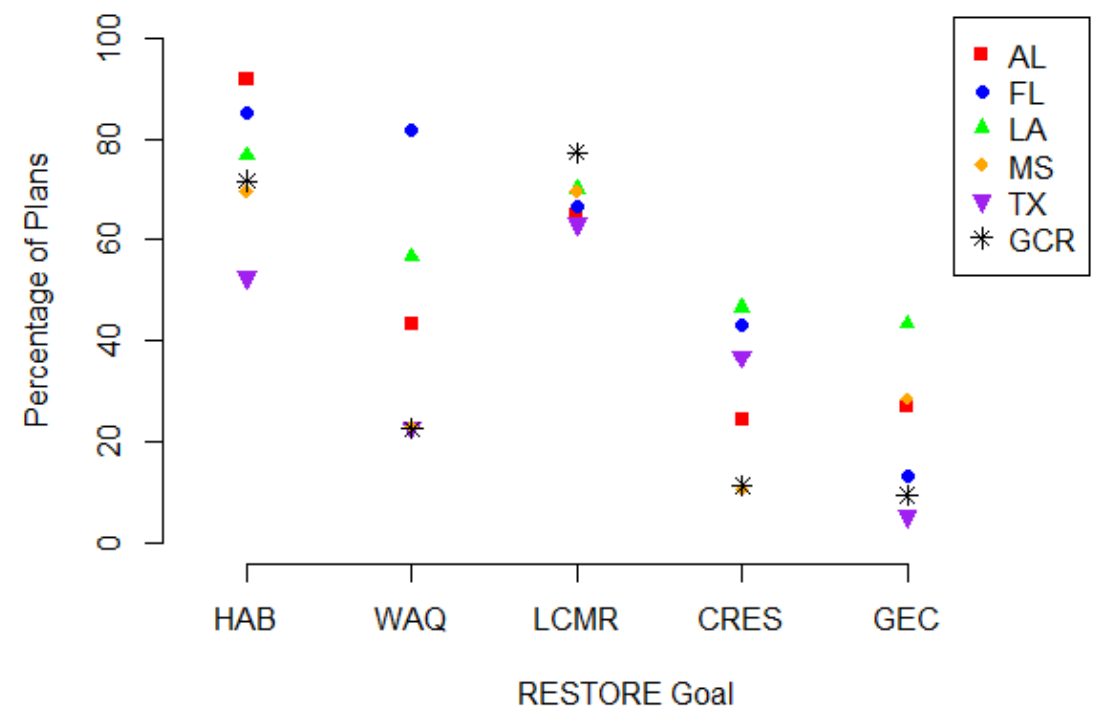

Figure 3. The focus of conservation plans in states spanning entire GCR categorized into the goals of assessment.

\subsection{RESTORE Goals by Subregion}

The percentage of plan focus on each RESTORE goal was dependent on political/geomorphological subregion (Figure 4), with the exception of LCMR and Gulf Economy. Across all subregions, LCMR was incorporated as a conservation priority by the majority of plans $(60-80 \%)$, while Gulf Economy was prioritized by the minority of plans (15-38\%). Only $20 \%$ of city-level conservation plans focused on Habitat, whereas the majority of plans from all other subregions included the Habitat goal. While Water Quality was a focus of nearly $100 \%$ of Basin-Watershed plans, plans from other subregions included Water Quality only 19-59\% of the time. The majority of City and County/Parish conservation plans included Community Resilience as a priority, while other subregions prioritized Community Resilience 17-35\%.

\section{Focus of RESTORE Goals by Geographic Extent}

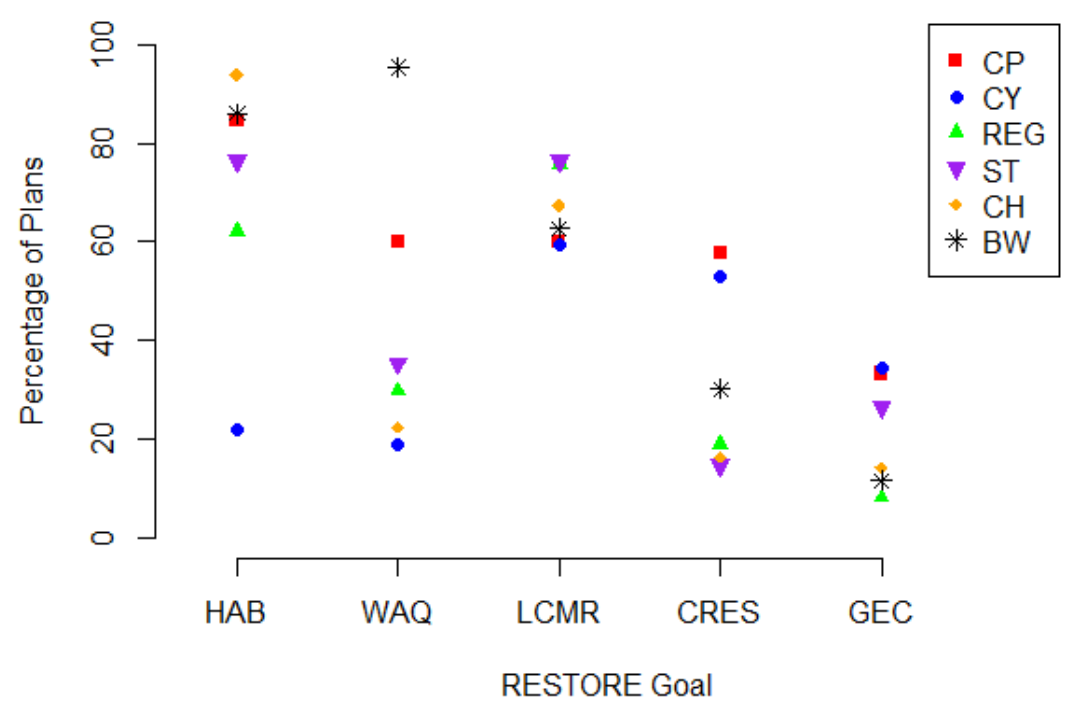

Figure 4. The focus of conservation plans in the Gulf of Mexico coastal states and entire GCR with respect to $\mathrm{CH}, \mathrm{BW}, \mathrm{CP}, \mathrm{CY}, \mathrm{REG}$, and ST. Focus is categorized into the goals of assessment described in Section 2.3. 


\subsection{RESTORE Goals by State and Subregion}

Of the 293 plans, 37 came from AL, 60 from FL, 30 from LA, 57 from MS, 56 from TX, and 53 from the GCR (more than one state). With respect to RESTORE goals, we identified that the majority of plans cataloged in AL focus on Habitat, Water Quality, and LCMR (Figure 5). County/parish and state-level plans in AL contained disproportionately greater priorities related to the Habitat goal relative to other goals. Regional plans focused with greater emphasis on priorities reflecting LCMR goals, whereas basin-wide priorities were the only spatial unit that incorporated elements of Water Quality over priorities in other goals.

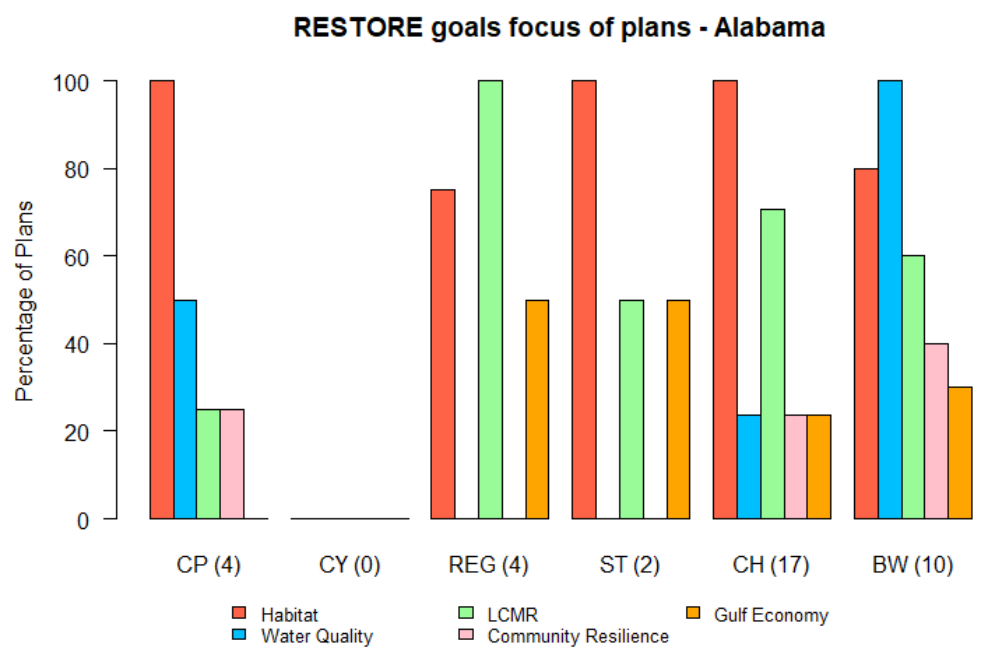

Figure 5. The focus of conservation plans in the state of Alabama with respect to CH, BW, CP, CY, REG, and ST. Focus is categorized into the goals of assessment described in Section 2.3.

In the state of Florida, we gathered 60 plans that are focused all or in part on some form of land conservation. With respect to RESTORE goals, we identified the majority of plans focus on Habitat, Water Quality, and LCMR, with some emphasis on Community Resilience at the regional and county/parish-level (Figure 6). Coastal habitat, basin and watershed, and county/parish plans contain priorities aligned with Habitat and Water Quality, whereas regional and state-level priorities also emphasize LCMR goals. Gulf Economy was not a substantial priority among FL plans overall, though economic priorities were found in over half of state-wide plans and a quarter of county/parish plans.

RESTORE goals focus of plans - Florida

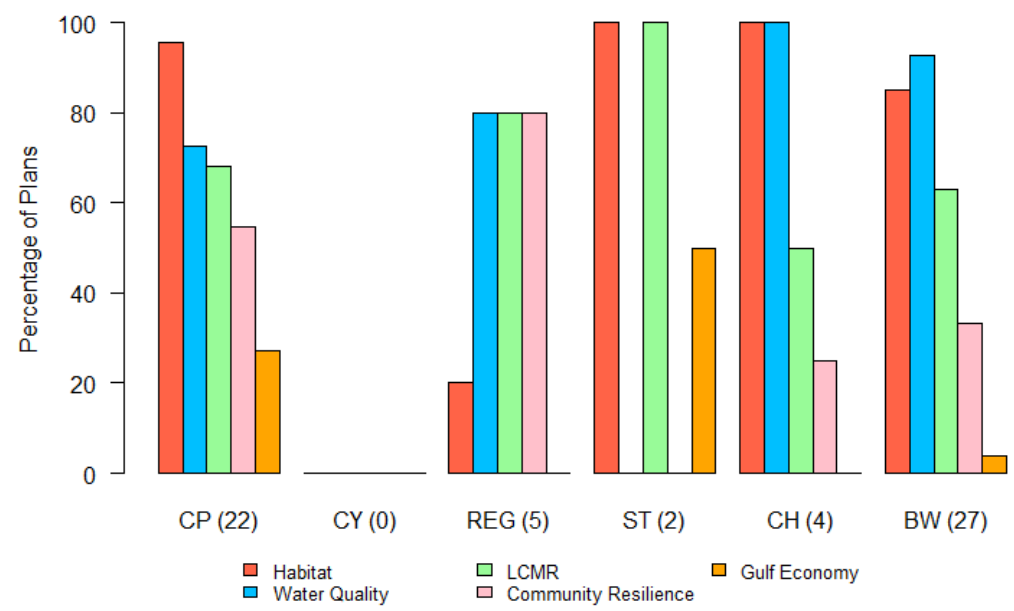

Figure 6. The focus of conservation plans in the state of Florida with respect to CH, BW, CP, CY, REG, and ST. Focus is categorized into the goals of assessment described in Section 2.3. 
In the state of Louisiana, we gathered 30 plans that are focused on some form of land conservation. With respect to RESTORE goals, we identified the majority of plans focus on Habitat, LCMR, Community Resilience, and Water Quality. Basin and watershed and county/parish plans are more aligned in Habitat and Water Quality, though county and parish-level plans prioritize Community Resilience and Gulf Economy over other goal categories (Figure 7). Priorities aligning with LCMR were also found in the majority of state and coastal habitat plans, but also in county/parish-level as well as basin and watershed plans.

\section{RESTORE goals focus of plans - Louisiana}

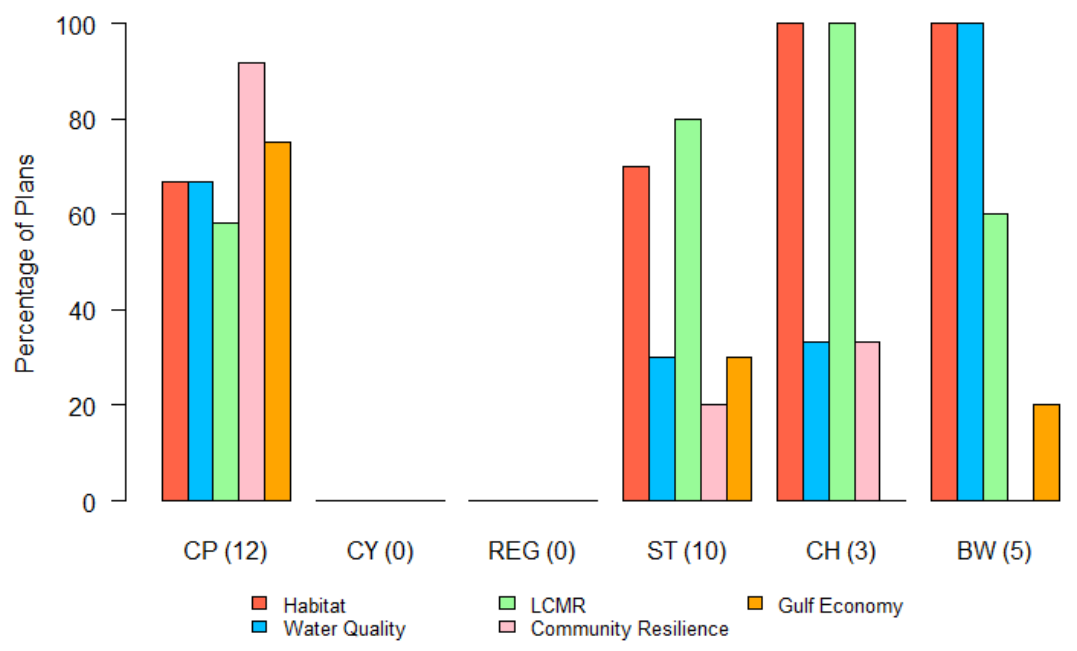

Figure 7. The focus of conservation plans in the state of Louisiana with respect to $\mathrm{CH}, \mathrm{BW}, \mathrm{CP}, \mathrm{CY}$, REG, and ST. Focus is categorized into the goals of assessment described in Section 2.3.

In the state of Mississippi, we gathered 57 plans that are focused on some form of land conservation. With respect to RESTORE goals, we identified the majority of plans focus on Habitat, Community Resilience, and LCMR (Figure 8). Note that MS had the greatest prevalence of plans that established priorities aligning with Community Resilience across planning scales compared to the remaining states. On the other hand, Water Quality and Gulf Economy priorities were not in the majority across any planning scale.

RESTORE goals focus of plans - Mississippi

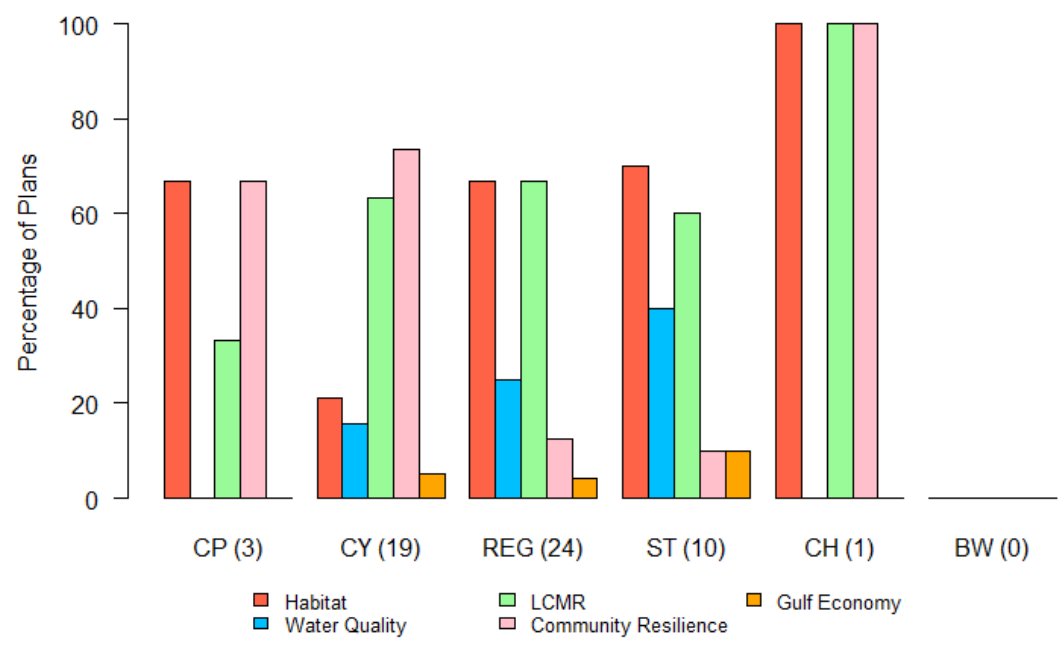

Figure 8. The focus of conservation plans in the state of Mississippi with respect to $\mathrm{CH}, \mathrm{BW}, \mathrm{CP}, \mathrm{CY}$, REG, and ST. Focus is categorized into the goals of assessment described in Section 2.3. 
In the state of Texas, we gathered 56 plans that focused on some form of land conservation. With respect to RESTORE goals, we identified the majority of plans focus on Habitat, LCMR, and Water Quality, though Gulf Economy was a driving force behind city plans (Figure 9). Water Quality priorities were only found in the majority of plans at the basin and watershed-level and state-level. Community Resilience priorities were not substantial across spatial planning scales.

\section{RESTORE goals focus of plans - Texas}

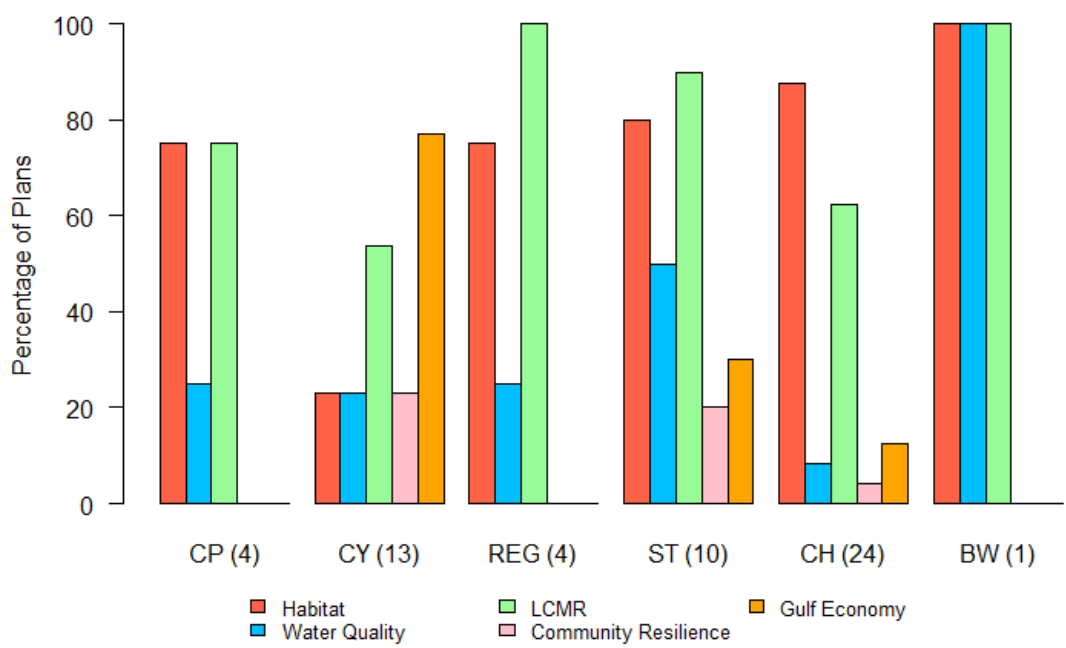

Figure 9. The focus of conservation plans in the state of Texas with respect to CH, BW, CP, CY, REG, and ST. Focus is categorized into the goals of assessment described in Section 2.3.

\section{Discussion}

Across all GCR states, land conservation was identified as a strategy for addressing Habitat and LCMR priorities more frequently than Community Resilience and Gulf Economy (Figures 3 and 5-9). Multistate (GCR-level) plans followed a similar pattern, with Habitat and LCMR priorities in far greater proportion compared to Water Quality, Community Resilience, and Gulf Economy. This is not unexpected, as typical strategies relative to revitalizing the Gulf economy often lean toward resource use, extraction, and workforce development and away from placing land in conservation and limiting development. While open space protection and utilizing green infrastructure is becoming a more recognized tool for enhancing community resilience [15-17], the number of plans identifying land conservation as a community resilience strategy was substantially fewer than those aiming to protect habitats, species, or waterbodies. That being said, priorities aligning with Community Resilience were identified in greater abundance in FL and LA compared to the remaining GCR states (Figures 3, 6 and 7). Likewise, Gulf Economy priorities were identified in greater proportion in LA relative to other GCR states.

Plans' focus on Water Quality was dependent on the state. Many of the conservation plans that target Water Quality reference Section 303(d) of the Clean Water Act and EPA's Water Quality Planning and Management Regulations (40 CFR Part 130), which requires states to identify impaired waterbodies within their boundaries. The D'Olive Watershed Management Plan (Appendix A-Plan 33) in AL mentions waterbodies listed under Section 303(d) and references urban development and excessive erosion and sedimentation as principal causes for impairment. The high variation in the plan focus on water quality by state may be due to different methods each state uses into assessing waterbody impairments, and differences in the proportion of their waterbodies they assess. For instance, MS has only assessed 7.2\% (lowest in GCR) while FL has assessed 20.2\% of its waterbodies (highest in GCR) [18]. The high percentage of FL plans focused on water quality is reflective of the state's emphasis on protecting water resources. FL has five water management districts (WMDs), which serve to manage water use and quality. These WMDs have much of their support and direction from the 
Florida legislature's passage of the Water Resources Act in 1972 and the Surface Water Improvement and Management (SWIM) [19]. The importance of Water Quality in FL is further validated by the size of their recreational fishing industry, and the proximity of human development to many waterways and unique ecosystems [20].

Across political and geomorphological subregions (subregions), Habitat and LCMR were high priority goals (Figure 4), which may be partially due to regulatory structures that mandate planning for particular resources by geographic scale. For instance, state wildlife agencies are tasked with drafting State Wildlife Action Plans (SWAPs), which identify both species (LCMR) and Habitat priorities that land conservation as a tool can address. Similarly, water quality and quantity planning are often accomplished at a basin or watershed scale because state Departments of Environmental Quality are required to draft these plans to meet EPA Clean Water Act regulations. It is widely accepted that watersheds should be of sufficient size to achieve economies of scale, take advantage of local government and technical expertise, and be viable for long-term management [21,22]. The same can be said for Hazard Mitigation plans, which are required by the Federal Emergency Management Agency and may identify conservation strategies as tools for addressing flood risk reduction and other Community Resilience priorities at the county or parish level because this is where the planning authority for those programs fall. Thus, priorities identified in plans at different subregions may be confounded with regulatory extents. Recognizing potential confounding effects, priorities aligning with RESTORE Council goals consistently emphasized Habitat and LCMR across most subregions and states.

In contrast, priorities aligning with Community Resilience and Gulf Economy goals were disproportionately underrepresented in plans we reviewed, though more prevalent in plans at the city- and county-level or parish-level compared to other subregions (Figure 4). Across subregions, plans cataloged in LA prioritized Community Resilience and Gulf Economy goals the most compared to the other Gulf States (Figure 7). LA's relatively strong focus on Community Resilience and Gulf Economy makes sense as many of the plans cataloged refer to subsidence, hurricanes, and sea-level rise as threats to critical community infrastructure, with frequent mention of Hurricane Katrina as a recent example for why investments in conservation and other land-use planning efforts are desirable (Appendix A-Plans 253, 255, and 258). The Lafourche Parish Comprehensive Resiliency Plan mentions strong support by constituents for "the need to preserve wetlands, plan for anticipated future land loss and for coastal restoration" in order to make community resilience and economic prosperity within the parish a reality (Appendix A-Plan 253).

City-level plans show a relatively strong focus on Community Resilience and show little to no focus on ecological goals (i.e., Habitat and Water Quality). The focus on Community Resilience is natural for city planning, and land conservation priorities found within city plans would likely target human welfare (e.g., system resilience to flood risk reduction, human health, and well-being) [15-17,23,24]. The number of plans from urban centers reviewed for this work was fewer than nonurban plans; nevertheless, the urban community resilience plans always include increasing urban green space. Planning typically happens at these scales because the lead planning organizations have access/authority over a political boundary, funding source, or tool kit. Conservation decision makers from various federal-, state-, county-, and city-level agencies and profit/nonprofit organizations address different levels of ecological and economic stressors; and they generally work within a constructed management framework. Community Resilience planning is perhaps more effective at smaller extents such as county/parish or city because problems such as infrastructure integrity or protection from natural calamities do not often have solutions that are practical to carry out across large geographic extents. Funding for resilience planning has increased post-Hurricane Katrina in the Gulf. The United States Housing and Urban Development, Federal Emergency Management Agency, National Oceanic and Atmospheric Administration, and others have invested substantial resources in LA and MS to emphasize resilience planning, and this trend appears to be increasing in TX and FL. LA and TX 
showed priorities more in alignment with the Gulf Economy, which may be potentially linked to strong oil economies and potential for resource-dependent population losses along coastal areas.

The plans' objectives may reflect the most direct threats, real or perceived, concerning the given scope of the planning area. The distinction between city- and county/parish-level plans may demonstrate differences in how respective economic drivers (urban and rural) connect to their environments. Along the Gulf coast, a substantial portion of urban economies are rooted in commercial, financial, and cultural activities, while many rural economies have foundations in agriculture and natural resources. As such, the economic wellbeing of counties and parishes often have close ties to ecosystem health, whereas city economies are often less dependent on environmental quality. In rural communities, agricultural lands and other natural resources are plentiful, protecting water resources and habitats may be more efficacious. Likewise, for cities, focusing on resilience provides insurance against threats to infrastructure, such as floods and storms, which could undermine their economy.

The associated web application (http://bit.ly/sca_gulf) provides the RESTORE Council, state and federal agencies, NGOs, and private landowners a means to understand and visualize past, existing, and future land conservation actions within their geography of interest and across the GCR. The tool can also provide the associated rationale for each conservation action. The catalog and tool can also be used to explore where and how land conservation can complement currently protected land. This tool, and our methodology of cataloging plans, could be applied to other regions of interest to help understand conservation priorities of the region of interest. The RESTORE framework adapted in this study could be replaced with other goals of conservation that may reflect the desires of the region of interest. Acknowledging that our catalog of plans is not exhaustive, the tool has been built to be dynamic so that users can contribute other existing plans not currently inventoried.

However, there may be bias in this identification of Water Quality priority prevalence in Florida due to the fact that Florida's Water Management Districts make Surface Water Improvement, and Management plans (Appendix A-Plans 329, 333-337, 340-346, and 349-352) that are easily accessible through centralized websites, while in other states access to watershed planning documents requires a deeper exploration of available internet sources. For example, Watershed Protection Plans in Texas are authorized through multiple authorities including the Texas State Soil and Water Conservation Board as well as the Texas Commission on Environmental Quality and can be difficult to readily locate.

In addition to the aforementioned potential for confounding effects of geo-extent with regulatory jurisdiction, sampling bias toward conservation-oriented planning documents may be causing underrepresentation of local development plans, which by their nature may contain a minimal emphasis on Habitat and LCMR priorities and much more focus on Community Resilience and Gulf Economy. We encourage careful use of these findings, and only with the understanding that this inventory of plans, though extensive, was not exhaustive, and analytical outputs should be interpreted accordingly.

This study mainly focused on the total number of plans as an indicator for the presence of focus of each RESTORE Council goal. However, there are exceptions in the GCR, for example, the state of Louisiana has a master plan that implements a large number of conservation actions each of which could be individual conservation plans in other localities (Appendix A-Plan 245). Another indicator could be the investment of financial resources to address these goals. Since the plans and projects proposed in GCR are cumulative and typically focus on multiple goals, it is challenging to differentiate the information on funds being spent per individual RESTORE goal. Thus the analysis based on a number of plans is a safe alternative, and future research should examine ecosystem services provided by plans and projects at a goal-level to further maximize efficiencies in funding expenditures.

\section{Conclusions}

This catalog of land conservation plans and its associated online tool is the first of its kind for the GCR and shows the diversity of motivations to conserve land across the region. From our cataloging exercise, we realized a need for a centralized database across the GCR for conservation priorities 
and planning. One could adapt our tool and methods for cataloging plans to better understand conservation goals in other regions of interest. By developing a catalog with the use of conservation goals that are relevant to the desired region, one could achieve a similar holistic understanding for how the goals are being met in that region.

The observed conservation motives from the catalog provide a baseline, with respect to the RESTORE Council goals, for what land conservation efforts exist in the GCR, and may help clarify gaps in conservation as an impetus for future land protections. Collectively, land conservation efforts in the GCR address all of the RESTORE goals; however, there appear to be strong associations among RESTORE goals and originating geographic extent of the plans. Whereas conservation plans address Habitat and LCMR across the GCR at relatively even rates, focuses on Water Quality, Community Resilience, and Gulf Economy appear to be more dependent on locality. For instance, the state of Florida has a high percentage of plans focused on improving water quality and quantity across multiple subregions, and Louisiana has a very high percentage of county/parish plans with a focus on Community Resilience and Gulf Economy (Figure 7). City and county/parish plans have a similar proportion of focus on LCMR, Community Resilience, and Gulf Economy, but substantially differ in focus on Habitat and Water Quality. These outcomes of our analysis highlight distinctions and similarities in conservation priority across the GCR, and conservation planners may use this information to guide future conservation actions that enhance protections for the region's diverse landscape, species, and economic activity. Acknowledging the distinctions in percentage of plans focused on RESTORE goals, encouraging better representation of certain priorities from plans across subregions could be accomplished with more integration of ecological and socioeconomic values [25]. For instance, a coastal area may be of interest for conservation not only for its use by a diverse group of species, but also to provide flood mitigation for a nearby community. In this case, the simultaneous consideration of biodiversity and flood mitigation could optimize the value of the conservation action. A follow-up evaluation that examines and evaluates the regulatory framework(s) and resource structures guiding the development of planning efforts within states and across the GCR may help to illuminate geographic differences or goal disparities.

Author Contributions: A.L. conceived the idea of this paper. S.S., A.S., and J.L. performed the writing and analysis. J.R. led the initial inventory and synthesis of plans and contributed to writing. K.E. initiated the project and contributed to writing and revisions.

Funding: This research was funded by the United States Department of Interior, grant number F17AC00267.

Acknowledgments: This paper is a contribution of the Mississippi Agricultural and Forestry Experiment Station and the Forest and Wildlife Research Center, Mississippi State University The authors would like to thank John Tirpak, Ben Wilson, Chris Pease, Matt Snider, David Reeves, and Stephanie Sharuga from U.S Fish and Wildlife Service; Steve Ashby and Wes Burger from Mississippi State University; and Jessica Henkel from the Gulf Ecosystem Restoration Council for their contributions to this work

Conflicts of Interest: The authors declare no conflicts of interest.

\section{Appendix A}

Table A1. Summary of 352 plans that were included in the catalog. The plans are color coded by state or GCR: AL—light green; MS—blue; GCR—yellow; TX—orange; LA—gold; FL—dark green.

\begin{tabular}{|c|c|c|c|c|c|c|}
\hline & Code & State & Plan Name & $\mathrm{ACQ}^{1}$ & EAS $^{1}$ & STE $^{1}$ \\
\hline 1 & $\mathrm{BI}$ & $\mathrm{AL}$ & Alabama Barrier Island Restoration Assessment & 0 & 0 & 1 \\
\hline 3 & BI & AL & Dauphin Island Bird Habitat Acquisition and Enhancement Program & 1 & 1 & 1 \\
\hline 5 & $\mathrm{CZ}$ & $\mathrm{AL}$ & Alabama Coastal Area Management Program Section 309 & 0 & 0 & 0 \\
\hline 6 & $\mathrm{CZ}$ & AL & Alabama Coastal Impact Assistance Program & 1 & 1 & 1 \\
\hline 7 & $\mathrm{CZ}$ & $\mathrm{AL}$ & Mobile Bay Shore Habitat Conservation and Acquisition Initiative-Phase II & 1 & 1 & 1 \\
\hline 8 & $\mathrm{CZ}$ & AL & Alabama Coastal and Estuarine Land Conservation Program, Program Implementation Strategy & 1 & 1 & 1 \\
\hline 11 & $\mathrm{CZ}$ & AL & Gulf Highlands Conservation Acquisition & 1 & 1 & 1 \\
\hline 12 & $\mathrm{CZ}$ & $\mathrm{AL}$ & Bon Secour National Wildlife Refuge Acquisition & 1 & 1 & 1 \\
\hline
\end{tabular}


Table A1. Cont.

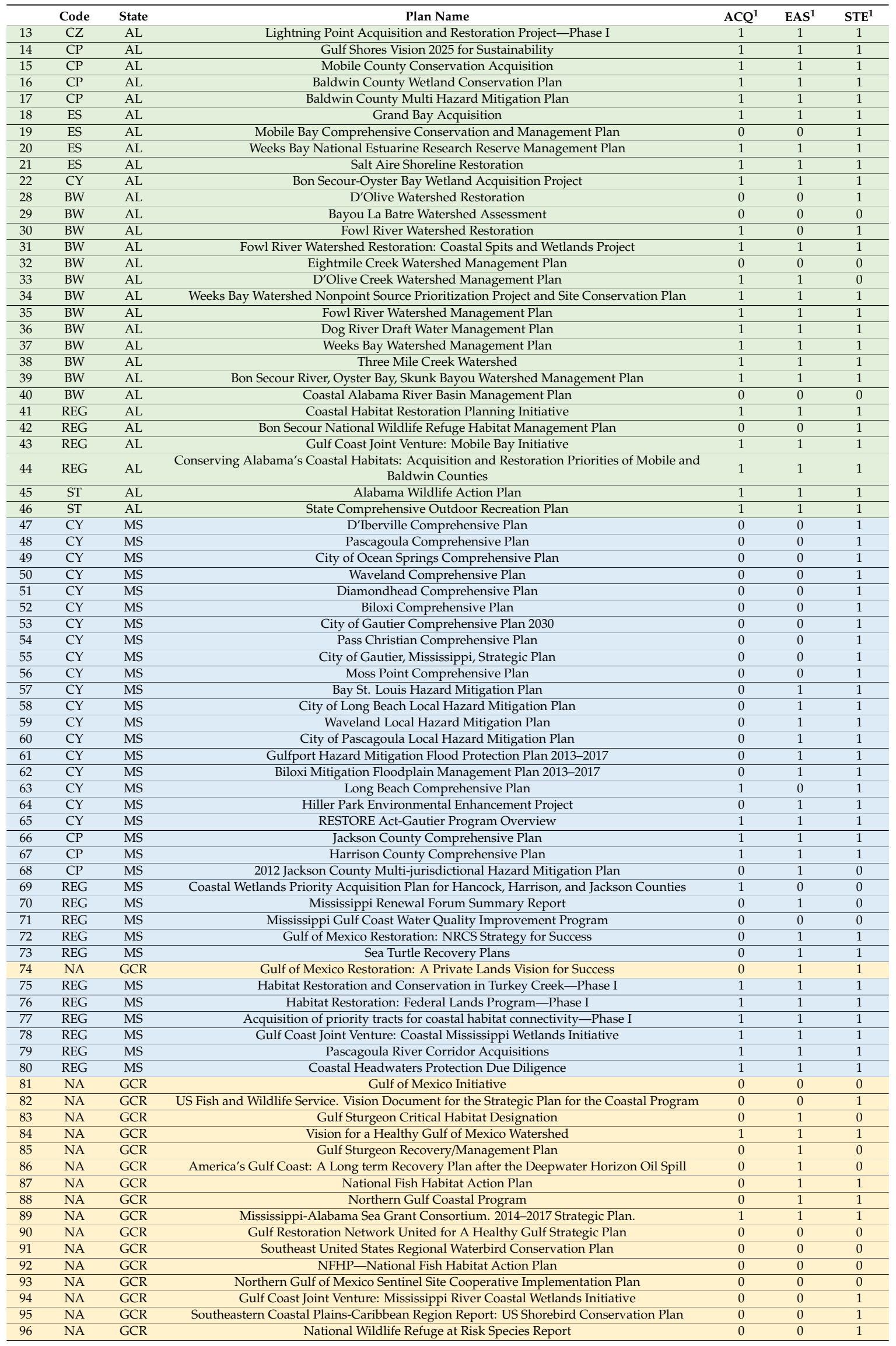


Table A1. Cont.

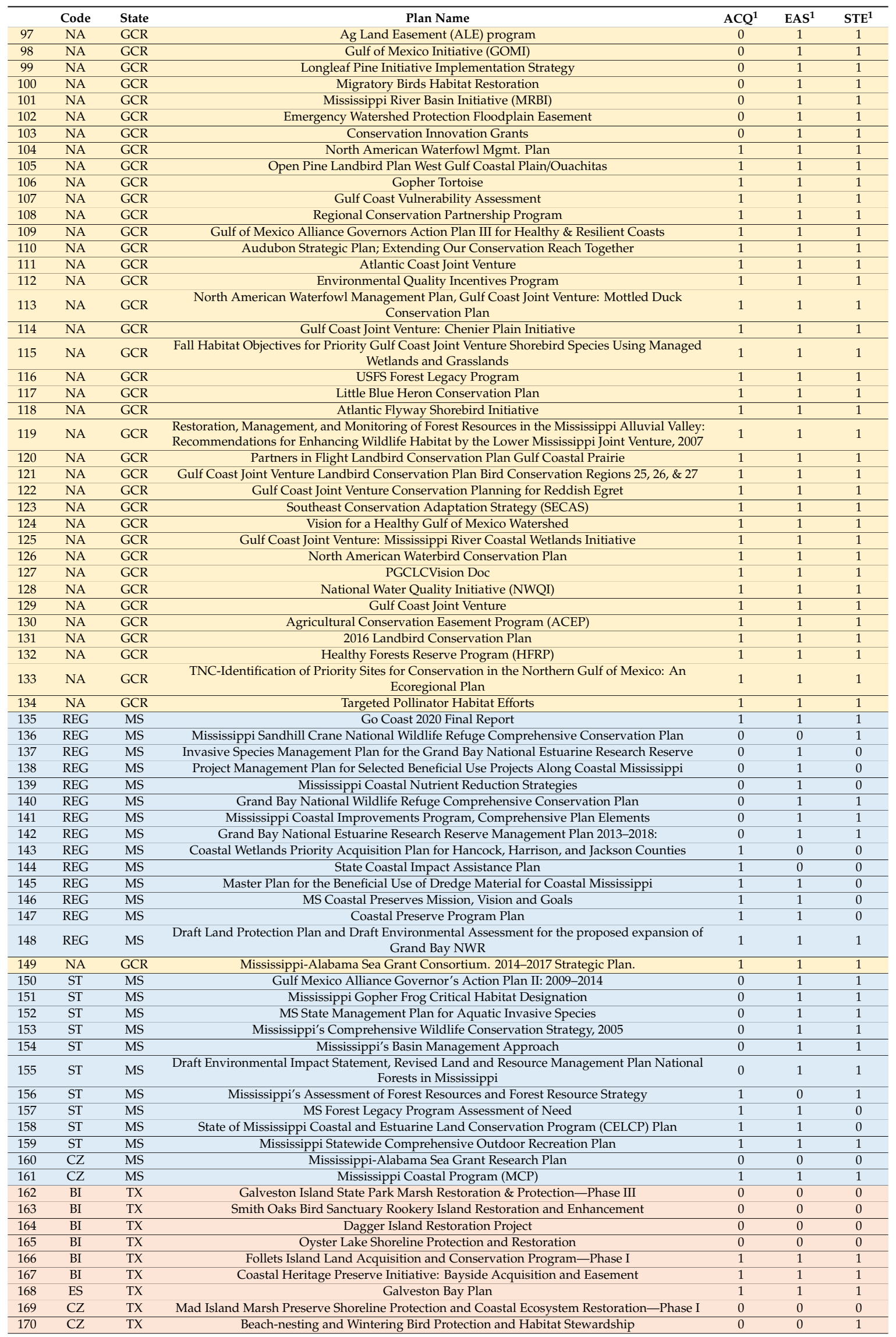


Table A1. Cont.

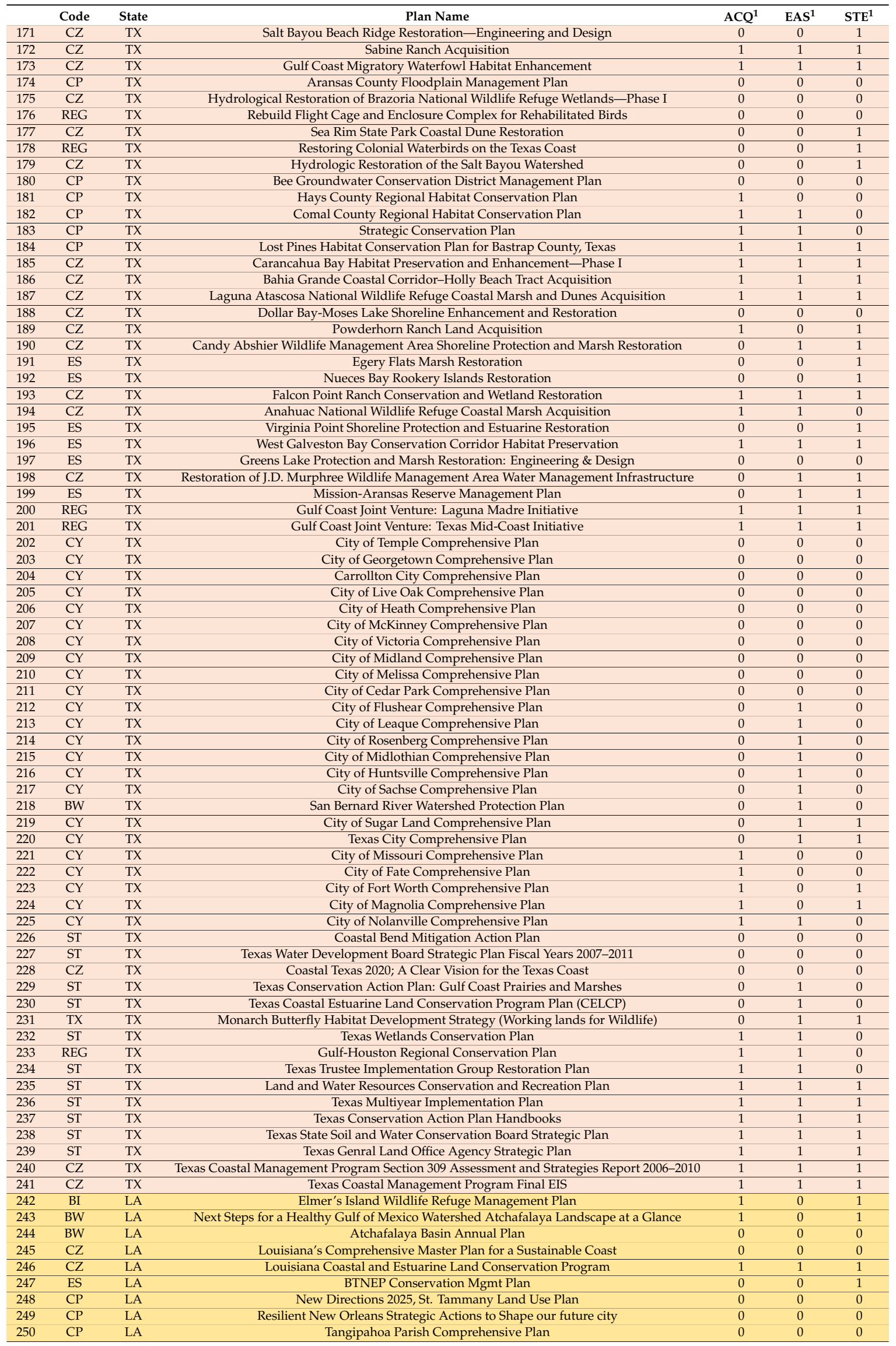


Table A1. Cont.

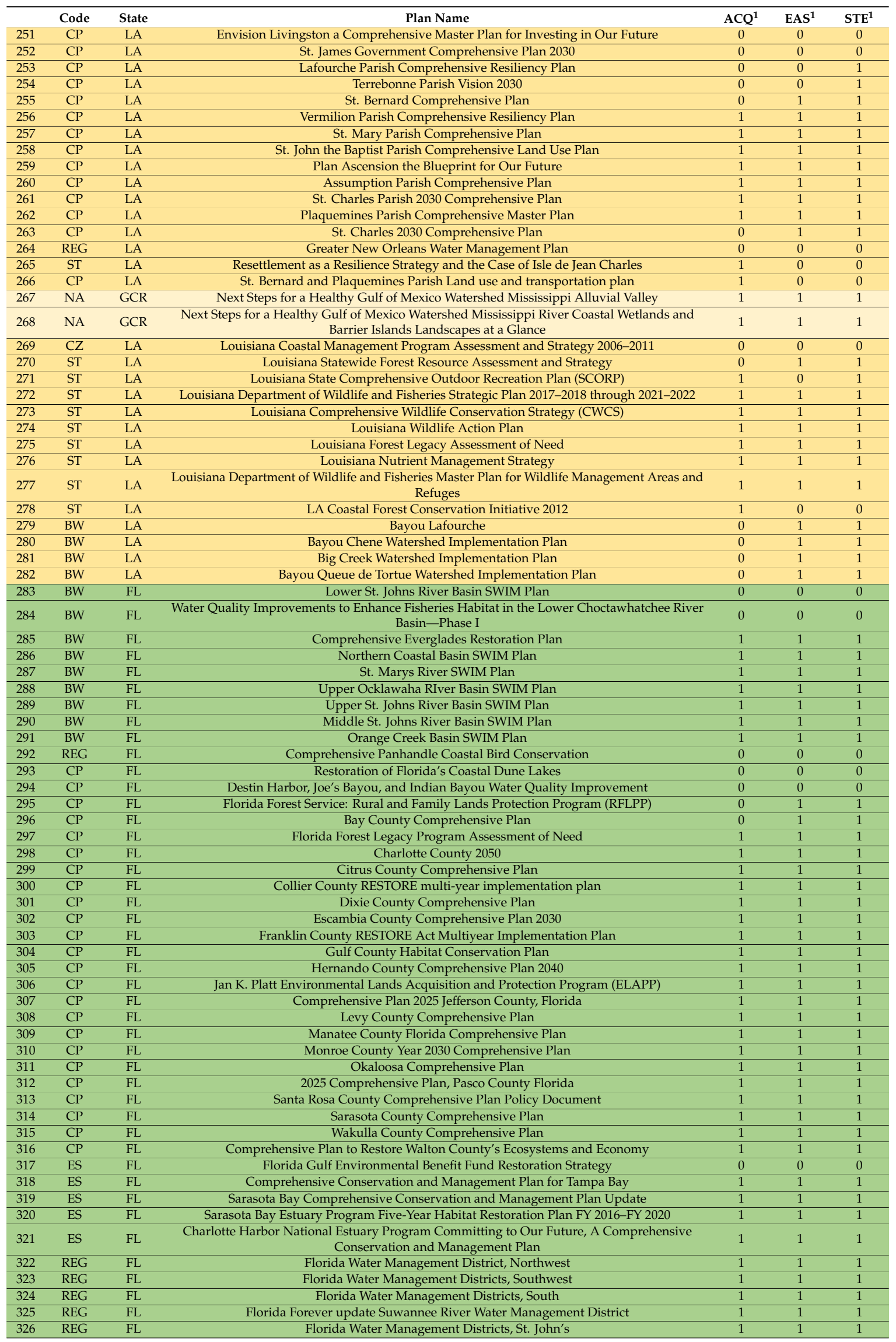


Table A1. Cont.

\begin{tabular}{|c|c|c|c|c|c|c|}
\hline & Code & State & Plan Name & $\mathrm{ACQ}^{1}$ & EAS $^{1}$ & STE $^{1}$ \\
\hline 327 & ST & FL & Florida Forever Five Year Plan (2017) & 1 & 1 & 1 \\
\hline 329 & BW & FL & St. Marks River and Apalachee Bay SWIM Plan & 0 & 0 & 0 \\
\hline 331 & BW & FL & Boggy Bayou Watershed Water Quality Improvement & 0 & 0 & 0 \\
\hline 332 & BW & FL & Restoration and Management of Escribano Point Coastal Habitat-Phase II & 0 & 0 & 0 \\
\hline 333 & BW & FL & Rainbow River SWIM Plan & 0 & 0 & 1 \\
\hline 334 & BW & FL & Lake Panasoffkee SWIM Plan & 1 & 0 & 0 \\
\hline 337 & BW & FL & Lake Tarpon SWIM Plan & 1 & 0 & 1 \\
\hline 338 & BW & FL & Peninsular Florida LCC Conservation Planning Atlas & 1 & 1 & 1 \\
\hline 339 & BW & FL & Florida Wildlife Action Plan & 1 & 1 & 1 \\
\hline 340 & BW & FL & Perdido River and Bay SWIM Plan & 1 & 1 & 1 \\
\hline 341 & BW & FL & Choctawhatchee River and Bay SWIM Plan & 1 & 1 & 1 \\
\hline 342 & BW & FL & Ochlockonee River and Bay SWIM Plan & 1 & 1 & 1 \\
\hline 348 & BW & FL & Florida Water Management Districts, Suwannee & 1 & 1 & 1 \\
\hline 349 & BW & FL & Lake Thonotosassa SWIM Plan & 1 & 1 & 1 \\
\hline 350 & BW & FL & Pensacola Bay System SWIM Plan & 1 & 1 & 1 \\
\hline 351 & BW & FL & St. Andrew Bay SWIM Plan & 1 & 1 & 1 \\
\hline 352 & BW & FL & Apalachicola River and Bay SWIM Plan & 1 & 1 & 1 \\
\hline
\end{tabular}

${ }^{1}$ ACQ: Acquisition; EAS: Easement; STE: Stewardship.

\section{References}

1. Felder, D.L.; Camp, D.K.; Tunnell, J.W., Jr. An Introduction to Gulf of Mexico Biodiversity Assessment; Texas A\&M Press: College Station, TX, USA, 2009; Volume 1.

2. Sherwood, M.G.; Meyer-Arendt, K.J.; Wicker, K.M. Land Loss in the Mississippi River Deltaic Plain. Trans. Gulf Coast Assoc. Geol. Soc. 1981, 31, 295-300.

3. Rabalais, N.N.; Turner, R.E.; Wiseman, W.J. Gulf of Mexico Hypoxia, A.K.A. "The Dead Zone”. Annu. Rev. Ecol. Syst. 2002, 33, 235-263. [CrossRef]

4. Feagin, R.A.; Sherman, D.J.; Grant, W.E. Coastal erosion, global sea-level rise, and the loss of sand dune plant habitats. Front. Ecol. Environ. 2005, 3, 359-364. [CrossRef]

5. Strong, A.M.; Bancroft, G.T. Patterns of Deforestation and Fragmentation of Mangrove and Deciduous Seasonal Forests in the Upper Florida Keys. Bull. Mar. Sci. 1994, 54, 795-804.

6. Reiger, J.F. American Sportsmen and the Origins of Conservation, 3rd ed.; Oregon State University Press: Corvallis, OR, USA, 2001; ISBN 978-0-87071-487-0.

7. Kamal, S.; Grodzińska-Jurczak, M.; Brown, G. Conservation on private land: A review of global strategies with a proposed classification system. J. Environ. Plan. Manag. 2015, 58, 576-597. [CrossRef]

8. USDA; NRCS. Gulf of Mexico Restoration-A Private Lands Vision for Success; United States Department of Agriculture: Washington, DC, USA, 2014.

9. 112th US Congress. RESTORE Act; Public Law Number 112-114, Code Number 4348, Section 1601-1608; 112th US Congress: Washington, DC, USA, 2012; pp. 184-203.

10. RESTORE Council Restoring the Gulf Coast's Ecosystem \& Economy-Gulf Coast Restoration Council Initial Comprehensive Plan. 2013. Available online: https://www.restorethegulf.gov/comprehensive-plan (accessed on 22 May 2019).

11. Pressey, R.L.; Whish, G.L.; Barrett, T.W.; Watts, M.E. Effectiveness of protected areas in north-eastern New South Wales: Recent trends in six measures. Biol. Conserv. 2002, 106, 57-69. [CrossRef]

12. Fisher, M.; Carver, S.; Kun, Z.; McMorran, R.; Arrell, K.; Mitchell, G. Review of Status and Conservation of Wild Land in Europe; The Wildland Reseach Institute, University of Leeds: Leeds, UK, 2010.

13. Cash, D.W.; Adger, N.W.; Berkes, F.; Garden, P.; Lebel, L.; Olson, P.; Pritchard, L.; Yound, O. Scale and cross-scale dynamics: Governance and information in a multilevel world. Ecol. Soc. 2006, 11, 8. [CrossRef]

14. Baillie, J.E.M.; Raffaelli, D.; Sillero-Zubiri, C. Levels of approach. In Key Topics in Conservation Biology 2; John Wiley \& Sons, Ltd.: Hoboken, NJ, USA, 2013; pp. 23-41. ISBN 978-1-118-52017-8. 
15. Aronson, M.F.; Lepczyk, C.A.; Evans, K.L.; Goddard, M.A.; Lerman, S.B.; MacIvor, J.S.; Nilon, C.H.; Vargo, T. Biodiversity in the city: Key challenges for urban green space management. Front. Ecol. Environ. 2017, 15, 189-196. [CrossRef]

16. Beyer, K.M.M.; Kaltenbach, A.; Szabo, A.; Bogar, S.; Nieto, F.J.; Malecki, K.M. Exposure to Neighborhood Green Space and Mental Health: Evidence from the Survey of the Health of Wisconsin. Int. J. Environ. Res. Public. Health 2014, 11, 3453-3472. [CrossRef] [PubMed]

17. Wolch, J.R.; Byrne, J.; Newell, J.P. Urban green space, public health, and environmental justice: The challenge of making cities 'just green enough'. Landsc. Urban Plan. 2014, 125, 234-244. [CrossRef]

18. EPA National Summary of State Information. Available online: https://ofmpub.epa.gov/waters10/attains_ nation_cy.control (accessed on 25 April 2019).

19. Florida Legislature. Florida Surface Water Improvement and Management Act; Florida Legislature; Chapter 373, Section 351, 4595; 1987. Available online: http://www.leg.state.fl.us/Statutes/ (accessed on 25 April 2019).

20. NMFS. Fisheries Economics of the United States Report, 2015; US Department of Commerce: Washington, DC, USA, 2015; p. 247.

21. Cooke, B.; Langford, W.T.; Gordon, A.; Bekessy, S. Social context and the role of collaborative policy making for private land conservation. J. Environ. Plan. Manag. 2012, 55, 469-485. [CrossRef]

22. Black, A.E.; Strand, E.; Wright, R.G.; Scott, J.M.; Morgan, P.; Watson, C. Land use history at multiple scales: Implications for conservation planning. Landsc. Urban Plan. 1998, 43, 49-63. [CrossRef]

23. Mehmood, A. Of resilient places: Planning for urban resilience. Eur. Plan. Stud. 2016, 24, 407-419. [CrossRef]

24. McPhearson, T.; Hamstead, Z.A.; Kremer, P. Urban Ecosystem Services for Resilience Planning and Management in New York City. AMBIO 2014, 43, 502-515. [CrossRef] [PubMed]

25. Bodin, O.; Crona, B.; Thyresson, M.; Golz, A.-L.; Tengo, M. Conservation success as a function of good alignment of social and ecological structures and processes. Conserv. Biol. J. Soc. Conserv. Biol. 2014, 28, 1371-1379. [CrossRef] [PubMed]

(C) 2019 by the authors. Licensee MDPI, Basel, Switzerland. This article is an open access article distributed under the terms and conditions of the Creative Commons Attribution (CC BY) license (http://creativecommons.org/licenses/by/4.0/). 